\title{
Right Ventricular Infarction With Cardiogenic Shock Treated With Percutaneous Cardiopulmonary Support A Case Report
}

\author{
Masahiko Suguta, MD; Hiroshi Hoshizaki, MD; \\ Makoto Anno, BS; Shigeto Naito, MD; Hiroshi Tada, MD; \\ Akihiko Nogami, MD; Shigeru Oshima, MD; Koichi Taniguchi, MD
}

\begin{abstract}
A patient with a right ventricular infarction was resuscitated with percutaneous cardiopulmonary support (PCPS), after attempts at reperfusion, high-dose inotropic support and intra-aortic balloon counterpulsation failed to improve the hemodynamic compromise. Emergency PCPS improved the cardiogenic shock and the reduced right ventricular load, allowing the ischemic right ventricle to recover in the setting of unsuccessful reperfusion. This case demonstrates the use of PCPS as a hemodynamic support device for spontaneous recovery of the ischemic right ventricle. PCPS may be a potential therapy for patients with right ventricular infarction. (Jpn Circ J 1999; 63: 813-815)
\end{abstract}

Key Words: Cardiogenic shock; Percutaneous cardiopulmonary support (PCPS); Right ventricular infarction

$\mathbf{N}$

umerous studies have reported that the presence of right ventricular infarction is one of the strongest predictors of mortality in patients with acute inferior myocardial infarction, 1,2 Although the usefulness of percutaneous cardiopulmonary support (PCPS) has been well demonstrated for patients with acute myocardial infarction or cardiogenic shock ${ }^{3-5}$ the efficacy of PCPS for right ventricular infarction is unknown.

\section{Case Report}

A 50-year-old Japanese man was admitted to the coronary care unit of Gunma Prefectural Cardiovascular Center with severe epigastric pain and dizziness that had persisted for more than $30 \mathrm{~min}$. The 12-lead ECG obtained immediately after admission showed significant ST-segment elevation in leads II, III and aVF. The systolic blood pressure was $40 \mathrm{mmHg}$, consistent with cardiogenic shock. Emergency coronary angiography revealed total occlusion of the proximal portion of the right coronary artery (RCA) with poor collateral circulation from the left coronary artery (Fig 1). Temporary right ventricular pacing at a rate of 60 beats $/ \mathrm{min}$ was performed for the treatment of complete atrioventricular block.

Direct percutaneous transluminal coronary angioplasty was performed during intra-aortic balloon counterpulsation. The patient was anticoagulated with heparin sodium during the procedure and an activated clotting time $>250$ s was maintained. The RCA was cannulated with an 8 Fr guiding catheter (CHAMP, C. R. BARD, Inc, Billerica, MA, USA), and a 0.014-in flexible guide wire (Commander, C. R.

(Received April 12, 1999; revised manuscript received May 27, 1999; accepted July 2, 1999)

Department of Cardiology, Gunma Prefectural Cardiovascular Center, Gunma, Japan

Mailing address: Masahiko Suguta, MD, Gunma Prefectural Cardiovascular Center, 3-12 Kameizumi, Maebashi, Gunma 371-0004, Japan. E-mail: Fast5150@aol.com
BARD) and a $4.0 \times 20 \mathrm{~mm}$ balloon (Hayate, Terumo, Tokyo) were easily passed through the culprit lesion in the proximal RCA; the target lesion was recanalized with balloon dilations of up to 10 atmospheres. However, the target lesion recoiled soon after balloon deflation and a coronary stent (Powergrip, Johnson \& Johnson Interventional Systems, Warren, NJ, USA) was then deployed with inflations of up to $12 \mathrm{~atm}$. Following stent implantation, coronary dissection was noted in the distal portion of the stent, limiting coronary flow. As a result, the right ventricular branches could not be visualized (Fig 1). No further interventions, including additional stent deployment and thrombolysis, were able to recanalize the RCA or restore coronary blood flow.

After the failed interventions, the surface ECG showed first degree atrioventricular block at a rate of 30 beats $/ \mathrm{min}$ and $0.7 \mathrm{mV}$ of ST-segment elevation in the right precordial leads (Fig 2). His chest radiogram showed no evidence of pulmonary edema. Transthoracic echocardiography revealed dilation and akinesis of the right ventricle. In contrast, the left ventricle had relatively good contractility and an ejection fraction of $40 \%$ (Fig 3 ). These findings led to a diagnosis of right ventricular infarction. Right heart hemodynamic measurements demonstrated a right atrial pressure of $18 \mathrm{mmHg}$, a mean pulmonary wedge pressure of $9 \mathrm{mmHg}$, and a cardiac output of $2.8 \mathrm{~L} / \mathrm{min}$, which indicated that the infarcted right ventricle had reduced the cardiac output, resulting in hemodynamic compromise.

Intravenous volume loading with plasma (saline: $0.4 \mathrm{~L} / \mathrm{h}$, albumin $50 \mathrm{ml} / \mathrm{h}$ ) together with high-dose catecholaminine infusion (dopamine: $10 \mu \mathrm{g} \mathrm{min}^{-1} \mathrm{~kg}^{-1}$, dobutamine: 5 $\mu \mathrm{g} \mathrm{min}-1 \mathrm{~kg}^{-1}$, and noradrenaline: $0.2 \mu \mathrm{g} \mathrm{min}^{-1} \mathrm{~kg}^{-1}$ ) were used for hemodynamic stabilization maintaining a mean pulmonary wedge pressure of about $12 \mathrm{mmHg}$. Intubation and mechanical ventilation was required to treat hypoxemia. In spite of these aggressive therapies, there was no improvement in the patient's hemodynamic status. An additional pacing electrode inserted through the subclavian vein 


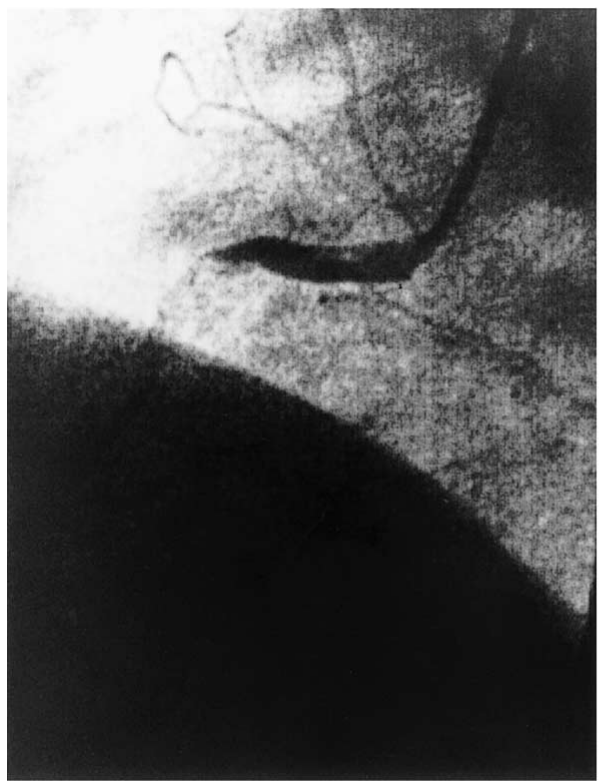

Pre

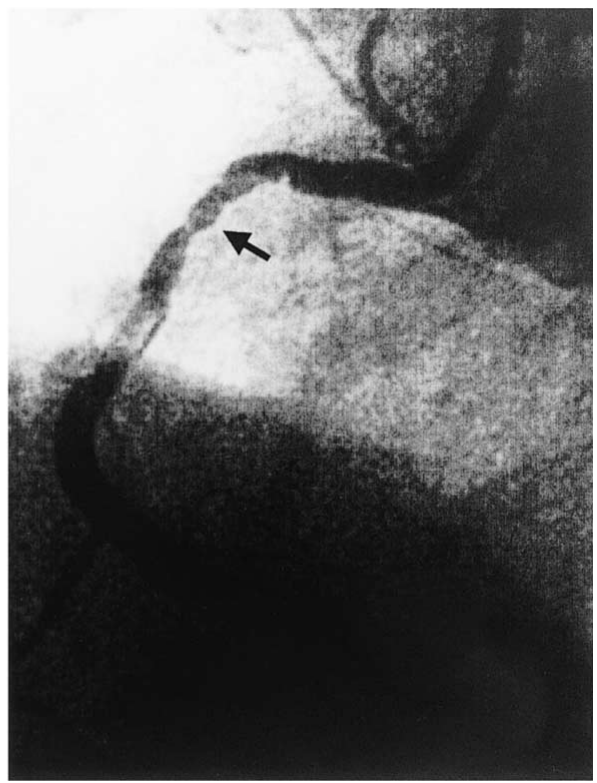

Post
Fig 1. Angiographs demonstrating total occlusion of the proximal portion of the right coronary artery. (Left) After unsuccessful stent deployment, there is a dissection in the distal portion of the stent. (Right) An arrow indicates the site of the stent.

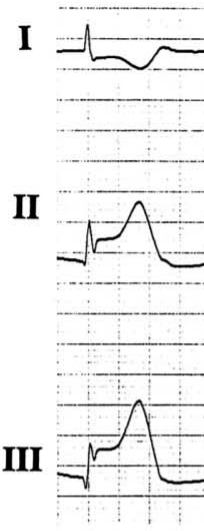

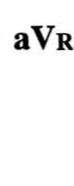

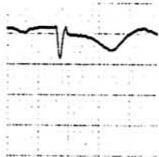

aVL

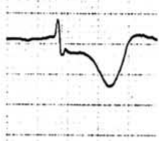

$\mathbf{a V F}$

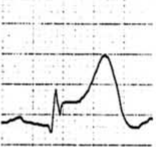

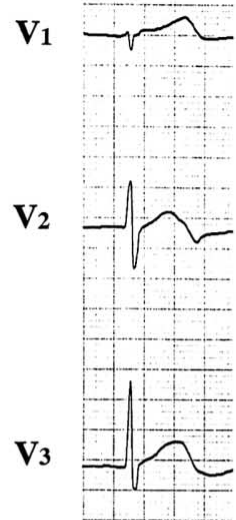

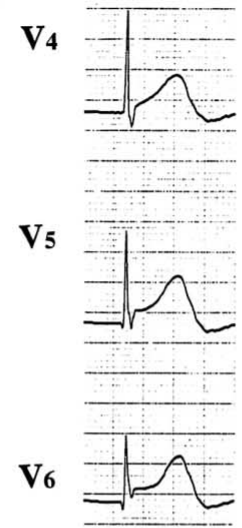

V3R

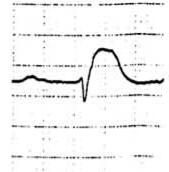

$\mathbf{V}_{4 R}$
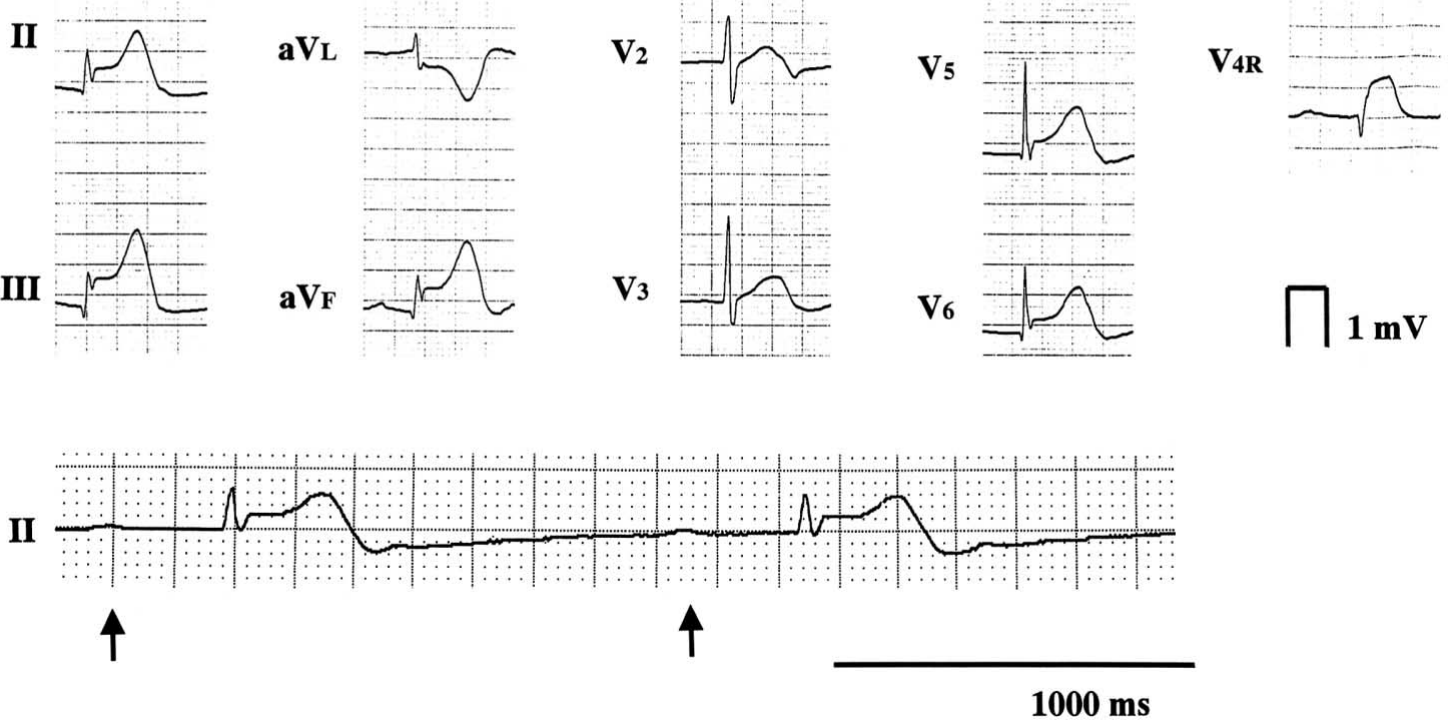

Fig 2. 12-lead electrocardiogram (Upper) and rhythm strip (Lower) after intervention. Significant ST-segment elevation is noted in leads V3R and V4R. Rhythm strip shows first degree atrioventricular block with a PR interval of $440 \mathrm{~ms}$; an arrow indicates the P waves.

with high outputs could not obtain adequate atrial capture in any part of the right atrium and only ventricular pacing was continued. Therefore, PCPS was instituted on the second day of admission. A $21 \mathrm{Fr}$ cannula and a $17 \mathrm{Fr}$ cannula (Medtronic Medicals, Anaheim, CA, USA) were inserted percutaneously into the femoral vein and artery, respectively, under fluoroscopic guidance. The venous outflow cannula was positioned in the right atrium. The PCPS system consisted of a centrifugal blood pump (Medtronic Bio-medicus, Eden Prairie, MN, USA), oxygenator (Maxima, Medtronic Blood Systems, Anaheim, CA, USA), and connecting lines. Flow rates of $4-6 \mathrm{~L} / \mathrm{min}$ were achieved with an improvement in hemodynamic stability and a restoration of the blood pressure to $80 \mathrm{mmHg}$. The PCPS was gradually weaned, based upon continuous right heart hemodynamic monitoring. Eight days after the PCPS was initiated, the cardiac output had increased to $4.58 \mathrm{~L} / \mathrm{min}$ without PCPS, and the patient was weaned off the PCPS completely. Normal sinus rhythm at a rate of 70 beats $/ \mathrm{min}$ with a PR interval of $200 \mathrm{~ms}$ was maintained and ventricular pacing was withdrawn. The length of hospital stay was 50 days with adequate rehabilitation. The patient has done well since that time and has had no evidence of right heart failure during the 6 months of follow up. 


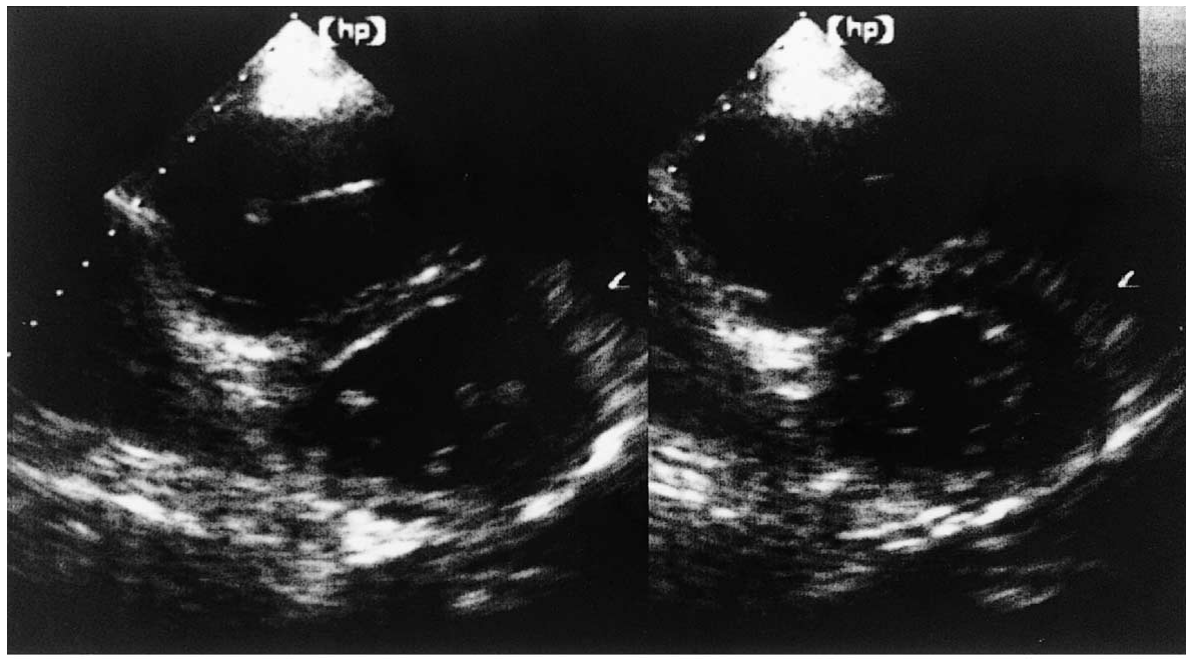

Diastole

\section{Discussion}

It has been shown that the use of PCPS for cardiogenic shock caused by myocardial infarction is extremely beneficial, 3 -7 although the efficacy of PCPS for right ventricular infarction remains unclear. Our experience reported here demonstrates the effectiveness of PCPS for right ventricular infarction, which is refractory to other conventional supportive measures.

Right ventricular infarction commonly complicates inferior myocardial infarction and may lead to right heart failure and hemodynamic collapse, 1,2 Bowers et al reported that complete reperfusion therapy of the RCA in the setting of right ventricular infarction improves the recovery of right ventricular function, and results in hemodynamic and clinical improvement! Therefore, revascularization of the infarct-related coronary artery in the setting of acute inferior infarction is recommended. On the other hand, several reports have shown that the right ventricle is more resistant to infarction than the left ventricle and that recovery of right ventricular function can be expected, even in patients with unsuccessful reperfusion of the infarct-related RCA!,2,6,7 These findings can be explained by the lower oxygen supply-demand characteristics, rich collateral vascular supply, and thinness of the right ventricular wall, as well as other poorly defined factors. 6.7 However, in the present patient, high-dose inotropic support and intra-aortic balloon counterpulsation did not improve the hemodynamic compromise after failed attempts at reperfusion. In Bowers' report, 7 of 12 (58\%) patients with unsuccessful recanalization of the right coronary artery died because of hypotension and reduced cardiac output, despite the use of inotropic support and intra-aortic balloon counterpulsation. Therefore, a more powerful resuscitative tool may be necessary for these patients to allow the recovery of the ischemic right ventricle. Furthermore, atrioventricular sequential pacing could not be achieved in the present patient. Although atrioventricular sequential pacing has been reported to improve the hemodynamics in right ventricular infarction 5 ischemic injury of the atrium often occurs in conjunction with right ventricular infarction ${ }^{8}$ and may cause unsuccessful atrial capture.
Systole
Fig 3. Transthoracic echocardiograph in the parasternal short-axis view during diastole (Left) and systole (Right), showing a dilated akinetic right ventricle. Note the D-shaped morphology of the left ventricular cavity during diastole (Left), indicating right ventricular volume overload.
Mooney et al have suggested that patients with cardiogenic shock caused by a complication of cardiac catheterization are well suited for PCPS when an anatomically correctable lesion is present? In the present patient, the application of PCPS shows its use as a hemodynamic support device for spontaneous recovery of the ischemic right ventricle with unsuccessful reperfusion. We consider that emergency PCPS improved the cardiogenic shock and reduced the right ventricular load, allowing the ischemic right ventricle to recover in the setting of unsuccessful reperfusion.

We conclude that aggressive mechanical cardiopulmonary support, such as PCPS, can be very useful for treating cardiogenic shock complicating right ventricular infarction.

\section{References}

1. Bowers TR, O'Neill WW, Grines C, Pica MC, Safian RD, Goldstein JA: Effect of reperfusion on biventricular function and survival after right ventricular infarction. $N$ Engl J Med 1998; 338: 933-940

2. Zehender M, Kasper W, Kauder E, Schontaler M, Geibel A, Olschewski M, et al: Right ventricular infarction as an independent predictor of prognosis after acute myocardial infarction. $N$ Engl $J$ Med 1993; 328: $981-988$

3. Obo H, Kozawa S, Asada T, Mukohara N, Higami T, Gan K, et al: Emergency percutaneous cardiopulmonary bypass support for acute myocardial infarction. Surg Today 1998; 28: 797-801

4. Shawl FA, Domanski MJ, Hernandez TJ, Punja S: Emergency percutaneous cardiopulmonary bypass support in cardiogenic shock from acute myocardial infarction. Am J Cardiol 1989; 64: 967-970

5. Love JC, Haffajee CI, Gore JM, Alpert JS: Reversibility of hypotension and shock by atrioventricular sequential pacing in patients with right ventricular infarction. Am Heart J 1984; 108: 5 -12

6. Laster SB, Ohnishi Y, Saffitz JE, Goldstein JA: Effects of reperfusion on ischemic right ventricular dysfunction: disparate mechanisms of benefit related to duration of ischemia. Circulation 1994; 90: $1398-1409$

7. Verani MS, Tortoledo FE, Batty JW, Raizner AE: Effect of coronary artery recanalization on right ventricular function in patients with acute myocardial infarction. J Am Coll Cardiol 1985; 5: 1029-1035

8. Alonso-Orcajo N, Izquierdo-Garcia F, Simmaro E: Atrial rupture and sudden death following atrial infarction. Int J Cardiol 1994; 46: 82 84

9. Mooney MR, Arom KV, Joyce LD, Mooney JF, Goldenberg IF, Von Rueden TJ, et al: Emergency cardiopulmonary bypass support in patients with cardiac arrest. J Thorac Cardiovasc Surg 1991; 101: $450-454$ 